\title{
APRESENTAÇÃO
}

\section{TEMPOS INTERESSANTES, TEMPOS DE AUTORITARISMOS E OBSCURIDADES?}

DOI: http://dx.doi.org/10.1590/2236-3459/73198

Maria Stephanou

(Co-editora)

Universidade Federal do Rio Grande do Sul, Brasil.

\section{$\cos 80$}

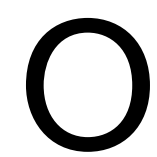

correu-nos iniciar a Apresentação deste número 52 de nossa Revista com o título sugestivo da obra biográfico-histórica de Eric Hobsbawm, intitulada "Tempos interessantes" (2002), na intenção de sugerir a nossos leitores uma inquietude face ao nosso tempo. Hobsbawm (2002), nascido no Egito, cuja profissão de historiador constituiu-se depois de sua fuga, e de sua família, para a Inglaterra, afirma que o século XX foi um século "breve", saturado de "tempos interessantes". Tendo nascido em 1917, ano sugestivo para os historiadores do mundo contemporâneo, e falecido em 2012, sua vida não apenas atravessou quase inteiramente o século XX, como também se estendeu pela primeira década do século XXI que, segundo suas palavras, começou sob o signo do autoritarismo e da obscuridade. Eis nossa inquietude e atenção ao presente.

Hobsbawm não foi escolhido ao acaso. Frequentou novamente nossas leituras recentes. No ano de 2017, que marca os cem anos da Revolução Russa, a remissão à sua obra foi quase inevitável. Talvez os jovens historiadores ainda não compreendam a dimensão e o significado da trajetória intelectual desse autor para a pesquisa historiográfica em escala mundial. Hobsbawm não é tão somente reconhecido como notável historiador marxista pela comunidade de historiadores identificada com esta corrente, mas a envergadura e importância de seu trabalho ultrapassa diversas perfilações teórico-ideológicas do campo historiográfico que the rendem reconhecimento.

Tempos interessantes, anúncio de obscuridade e autoritarismos a marcarem as primeiras décadas do presente século são, indiscutivelmente, formulações fecundas para inciter a reflexão sobre o presente, para compreender a história de nosso próprio tempo, como "observadores participantes" (HOBSBAWM, 2002, p. 11).

Em sua obra autobiográfica, não sobressai apenas o tom narrativo, mas a acuidade profundamente histórica, texto feito para pensar a si mesmo e seu tempo. Hobsbawm afirma que "o 
entrelaçamento da vida de uma pessoa com sua época e a interpretação das duas coisas juntas ajudam de maneira mais profunda a dar forma a uma análise histórica" (2002, p. 11), esta ao final quiçá independente de ambas, vida e época! O mundo à volta das pessoas e o passado, segundo o autor, não apenas dão forma à experiência de suas vidas, pois oferecem-lhes uma gama de escolhas, sempre limitadas, mas também circunscrevem a análise dos historiadores. Convém reafirmar tal entendimento face aos artigos publicados em cada um dos números de História da Educação: a gama de possibilidades interpretativo-compreensivas e seus limites estão postos igualmente para a produção historiográfica consubstanciada nos artigos veiculados em 52 números que perfazem vinte anos de nossa Revista.

Ora, não há qualquer demérito nessas assertivas. Reafirmam a contingência e historicidade da própria escrita da História e alertam para o fato de que não estamos ilesos aos efeitos de sua divulgação, o que aumenta, enormemente, nosso dever de ofício. Não pensemos que a história da educação seja um subcampo mais isento, porque supostamente voltado a uma realidade histórica de menos visibilidade no macro campo da ciência histórica. O que interpretamos, compreendemos, escrevemos como historiografia da educação, afeta não apenas o que pensamos do passado, mas como nos deparamos com o presente. Para Hobsbawm,

\begin{abstract}
Não se pode escapar ao passado, isto é, àqueles que o registram, interpretam, discutem e reconstroem. Nossas vidas cotidianas, os países em que vivemos e os governos que nos dirigem [questão de atualidade ímpar!], tudo isso está rodeado e inundado pelos produtos de minha profissão. O que entra para os livros escolares e para os discursos dos políticos a respeito do passado, a matéria para os escritores de ficção, de programas de televisão ou de vídeos vem, em última análise dos historiadores. Mais do que isso, a maioria dos historiadores, inclusive todos os competentes, sabe que ao investigar o passado, até mesmo o passado remoto, estão igualmente pensando e expressando opiniões a respeito do presente e suas questões, e falando a respeito delas. Compreender a história é importante tanto para os cidadãos como para os especialistas (...). Os historiadores não devem escrever somente para outros historiadores. (...) temos muito que fazer. (2002, p. 311 e 326)
\end{abstract}

Os artigos enfeixados neste número 52 investigam o passado e oferecem janelas e chaves de interpretação de uma gama variada de temas relevantes não apenas à compreensão do presente da Educação, em linhas muito amplas, mas sobretudo demonstram as múltiplas interseções desta com o mundo do trabalho, os campos político, religioso, militar, científico, cultural, editorial, dentre outros, em nosso país e em outros países examinados, particularmente a Itália, Portugal, o Reino Unido, o Chile, a Argentina, a Colombia e o México, contemplados em artigos deste número.

As investigações que sustentam essas escritas historiográficas abrangem os séculos XIX e XX, além do documento de rara importância produzido no século XVII, escrito por John Locke, intitulado "Alguns pensamentos referentes à Educação", apresentado por Eduardo Arriada e Elomar Tambara da UFPel.

Dois destaques são imperativos: primeiramente a entrevista com o Prof. Dr. Lúcio Kreutz, historiador da educação e pesquisador de reconhecida contribuição ao nosso campo, realizada pela Profa. Terciane Luchese, entrevista contemplada em nossa Seção Especial, cujo depoimento é fundamental por seu valor como documento histórico ao estudo da constituição e institucionalização do campo da História da Educação no Brasil, experiência de vida e época entrelaçados, como acima sugeriu Hobsbawm e como anuncia o texto de apresentação da mesma, pela Professora Luchese.

Em segundo lugar, o dossiê História da Educação Católica: produção e circulação de saberes pedagógicos, organizado pelas pesquisadoras Evelyn de Almeida Orlando e Paula Leonardi, cujas temáticas ainda são pouco exploradas em nossa área. O dossiê é composto por quatro artigos, que abordam diferentes práticas educativas e evangelizadoras da Igreja Católica, com centralidade à circulação de impressos, e abarcam o período 1930-1960. Os focos das investigações são variados, do bandeirantismo, passando pela Escola de Pais, movimento dos Focolares, até a interpretação da Escola Ativa pela ótica católica. Alexandra Lima, a partir de um periódico em particular, aborda o bandeirantismo brasileiro e suas relações com o catolicismo, particularmente na década de 1950, e destaca a participação feminina no processo. Maria José Dantas focaliza o movimento dos Focolares, especialmente 
contemplado em um periódico e discute as implicações eclesiais, pedagógicas e civis deste impresso. Evelyn Orlando e Helder Henrique Martins detém-se no exame do movimento Escola de Pais, de intelectuais e pais católicos. E Joaquim Pintassilgo, pesquisador português, examina um periódico de estudantes de Colégio católico em Portugal, em relação ao qual discute a idéia de "self-government» e de «educação integral», somados ao ideário da «Escola Ativa», de um projeto católico e conservador, que contribui para reforçar a identidade da instituição escolar em questão.

Treze artigos integram a terceira parte da Revista, cujas autorias são de pesquisadores brasileiros, de diferentes vinculações institucionais, assim como de pesquisadores de Portugal, Itália, Colômbia, Chile, Argentina. A diversidade dos temas, tempos e contextos reafirmam a vitalidade da pesquisa historiográfica da Educação e as múltiplas possibilidades de empreendimentos de estudo nesse campo: memórias e intelectuais; pensamento pedagógico; políticas educacionais; educação política; educação técnico-profissional; ensino secundário; militares e educação escolar; impressos e práticas de leitura; difusão, circulação e recepção de impressos; livros didáticos; preceitos morais, religiosos e educação; cultura material escolar; currículos e disciplinas escolares; professorado de primeiras letras; ensino de História.

Roberta Aline Sbrana e Marcus Vinicius da Cunha são autores do artigo Análise retórica das memórias de Paschoal Lemme; Berta Servat Poblete intitula seu artigo Origen, trayectoría y efectividad de la formación de enseñanza media técnico profesional en Chile; A Primeira Guerra Mundial na escrita de livros didáticos de História (Argentina, Brasil, Chile, México e Reino Unido), de autoria de Rogério Justino e Décio Gatti Júnior; Experiências docentes e culturas políticas: o professor de primeiras letras João Baptista Brandão Proença (5ª Comarca da Província de São Paulo/Província do Paraná. 1830-1860) intitula o artigo de Fabiana Garcia Munhoz e Diana Gonçalves Vidal; Anselmo Guimarães e Josefa Eliana Souza apresentam o trabalho $O$ "Americanismo" e a criação da cadeira de espanhol no ensino secundário brasileiro (1917-1926); Mónica Liset Valbuena Porras é autora do artigo Politicas educativas de los gobiernos liberales en la creación y organización de las escuelas normales del departamento de Boyacá (1930-1938); Anelise Martinelli Borges Oliveira e Raquel Lazzari Leite Barbosa são autoras de Um estudo histórico sobre o processo de implantação do Colégio Tiradentes da Polícia Militar de Uberaba, MG (19641968); Ilsa do Carmo Vieira Goulart intitula seu artigo "Nas publicações sobre livros de leitura no início do século XX: traços de uma cultura material escolar"; Autoridade, disciplina e aplicação de castigos nas representações de professores (1910-1930) é o artigo cujos autores são Geisa Magela Veloso, Rafael Baioni do Nascimento e Mônica Maria Teixeira Amorim; Educação política no Brasil e na Itália: duas histórias, muitos problemas comuns é o artigo cuja autoria é de Marcus Aurelio Taborda de Oliveira e Paolo Bianchini; Felicitas Acosta apresenta o texto intitulado Ensinar História da Educação: reflexões em torno de uma proposta; Cristinne Leus Tomé e Josiane Brolo Rohden compartilham a autoria do artigo $\mathrm{O}$ discurso do progresso e a educação na história de Sinop - Mato Grosso: "como é bom alargar fronteiras de nossa pátria!"; Wilson Ricardo Antoniassi de Almeida apresenta o texto cujo título é Professor Leovegildo Chagas Santos (1955): patrono do Terceiro Grupo Escolar de Limeira, Estado de São Paulo.

As instituições nacionais de vinculação dos pesquisadores/autores contempladas neste número são: Universidade de Caxias do Sul; Universidade de São Paulo; Universidade Federal de Lavras; Universidade Federal de Minas Gerais; Universidade Federal de Pelotas; Universidade Federal do Rio Grande do Sul; Universidade Federal de Rondônia; Universidade Federal de São Carlos; Universidade Federal do Sergipe; Universidade Federal de Uberlândia; Universidade Estadual de Montes Claros; Universidade Estadual Paulista; Universidade Estadual do Rio de Janeiro; Universidade Estadual Paulista Júlio de Mesquita Filho; Universidade do Estado de Mato Grosso; Pontifícia Universidade Católica do Paraná; Pontifícia Universidade Católica do Rio Grande do Sul; Instituto Federal de Educação, Ciência e Tecnologia do Tocantins.

$\mathrm{E}$ as instituições do exterior cujos autores contam neste número são: Universidade de Lisboa, Portugal; Instituto Politécnico de Portalegre, Portugal; Pontificia Universidad Católica de Chile; Universidad Pedagógica y Tecnológica de Colombia; Universidad Nacional de La Plata e Universidad Nacional de General Sarmiento, Argentina; Università degli Studi di Torino, Itália. 
Após os artigos de submissão individual, a Revista publica duas resenhas, uma de Maria Helena Camara Bastos, intitulada Um olhar sobre a história da creche na Europa (séculos 19 e 20); e outra de Juliana dos Santos Rocha, cujo título é Denunciar e anunciar: a menina que utilizou as redes sociais para enfrentar o descaso com a escola. E a parte final, como já destacamos anteriormente, contempla a publicação de documento relevante à História da Educação, de autoria de John Locke, apresentado pelos pesquisadores Eduardo Arriada e Elomar Tambara.

$\&$

"Tempos interessantes", do passado e do presente. Inspirando-nos em Hobsbawm (2002), aqui retomado, voltamos a insistir na urgência de nossa reflexão comprometida com a superação dos obscurantismos que proliferam e dos autoristarismos que insistem em reemergir, na Educação, na sociedade, na vida de nossa época.

Afinal,

O teste de um historiador, ou historiadora, é saber se é capaz de responder a perguntas, especialmente do tipo "E se...?" sobre temas de significação passional para si e para o mundo, como se fossem jornalistas descrevendo coisas há muito acontecidas - porém também não como estranhos, mas como pessoas profundamente envolvidas. Não são perguntas sobre a história real, que não trata daquilo que gostaríamos, mas sobre o que aconteceu e talvez pudesse ter acontecido de outra forma, mas não foi assim. São perguntas sobre o presente e não sobre o passado, que é justamente o motivo pelo qual são importantes para quem vive no início de um novo século, velho ou jovem. (HOBSBAWM, 2002, p. 454)

Parafraseando François Hartog (2013, p. 254) quando este rende homenagem à Michel de Certeau, pensamos também que aqui nos limitamos a ser apenas viajantes nos textos de Eric Hobsbawm, nada além de passantes. Viajantes-leitores. E, possivelmente tenhamos sido leitores nômades, que deslocaram os sentidos dos textos aqui inspiradores com o intuito maior de "incitar a pensar" sobre os acontecimentos deste tempo que misturam nosso ofício de historiadores com a experiência de nossa época.

\section{Referencia}

HARTOG, François. Evidencia da História. O que os historiadores veem. Tradução de Guilherme João de Freitas Teixeira. Belo Horizonte: Autentica Editora, 2013.

HOBSBAWM, Eric. Tempos interessantes. Uma vida no século XX. Tradução de S. Duarte. São Paulo: Companhia das Letras, 2002.

MARIA STEPHANOU é professora titular da Faculdade de Educação da Universidade Federal do Rio Grande do Sul. Pesquisadora do CNPq, atua junto ao Programa de Pós-Graduação em Educação na linha de pesquisa História, memória e educação. Doutora em Educação pela Ufrgs, realizou seu pós-doutoramento junto ao Institut Français d'Éducation, IFÉ, França. Atua como co-editora de História da Educação desde 2011.

Endereço: Rua Dr. João Palombini, 144 A - 91751-150 - Porto Alegre/RS - Brasil

E-mail: mastephanou@gmail.com 